\title{
Treatment with double dose of omeprazole increases $\beta$-endorphin plasma level in patients with coronary artery disease
}

Jacek Budzyński², Grzegorz Pulkowski², Maria Kłopocka ${ }^{1}$, Beata Augustyńska ${ }^{3}$, Anna Sinkiewicz Karol Suppan', Jacek Fabisiak', Marcin Majer², Maciej Świątkowski ${ }^{1}$

1Department of Gastroenterology, Vascular Diseases and Internal Medicine, Nicolaus Copernicus University in Toruń, Collegium Medicum in Bydgoszcz, Poland ${ }^{2}$ Clinical Ward of Vascular Diseases and Internal Medicine,

Doctor Jan Biziel University Hospital no. 2, Bydgoszcz, Poland

${ }^{3}$ Department of Psychiatric Nursing, Nicolaus Copernicus University in Toruń,

Collegium Medicum in Bydgoszcz, Poland

4The Outpatient Phoniatrics Department, Doctor Jan Biziel University Hospital no. 2

in Bydgoszcz, Poland

Submitted: 5 January 2009

Accepted: 22 January 2009

Arch Med Sci 2010; 6, 2: 201-207

DOI: 10.5114 /aoms.2010.13896

Copyright ( 2010 Termedia \& Banach

\author{
Corresponding author: \\ Jacek Budzyński, MD, PhD \\ Department \\ of Gastroenterology, \\ Vascular Diseases \\ and Internal Medicine \\ Nicolaus Copernicus \\ University in Torun \\ Collegium Medicum \\ in Bydgoszcz \\ Ujejskiego 75 Street \\ 85-168 Bydgoszcz, Poland \\ Fax: +48 523714912 \\ E-mail: budz@cps.pl
}

\begin{abstract}
Introduction: The proton pump inhibitor empirical trial, besides the analysis of symptoms, is the main method in the diagnosis of gastro-oesophageal reflux disease-related chest pain. $\beta$-Endorphin acts as an endogenous analgesia system. The aim of the study was verify whether $\beta$-endorphin plasma level is affected by omeprazole administration and influences the severity of anginal symptoms and outcome of the "omeprazole test" in patients with coronary artery disease (CAD) and chest pain of suspected non-cardiac origin.

Material and methods: Omeprazole was administered to 48 patients with CAD in a randomized, placebo-controlled, crossover study design. At the beginning of the study, and again after the 14-day omeprazole and placebo treatment, the $\beta$-endorphin plasma concentration was determined.

Results: The level of plasma $\beta$-endorphin after the administration of omeprazole was significantly greater than at the start of the study and following the placebo. Responders to omeprazole had an average lower $\beta$-endorphin plasma concentration than subjects who failed to respond to this therapy. Subjects with symptoms in class III (according to the Canadian Cardiovascular Society classification) after omeprazole administration had a greater $\beta$-endorphin plasma level than subjects in class II for anginal symptom severity.

Conclusions: Fourteen-day therapy with a double omeprazole dose significantly increases the $\beta$-endorphin plasma concentration in patients with CAD. Circulating $\beta$-endorphin does not seem to be involved in the mechanism for the "omeprazole test" outcome, although an individually different effect on pain threshold cannot be excluded.
\end{abstract}

Key words: $\beta$-endorphin, omeprazole test, chest pain, coronary artery disease.

\section{Introduction}

Chest pain is one of the most common symptoms in health care. The mean annual prevalence of angina-like retrosternal chest pain of non- 
cardiac origin (non-cardiac chest pain, NCCP) in the general population is approximately $25 \%[1,2]$. The most frequent cause of NCCP is gastrooesophageal reflux disease (GORD), which frequently coexists with coronary artery disease (CAD) [3]. GORD-related chest pain may be indistinguishable from ischaemic cardiac pain [1-3]. After excluding its cardiac source, empirical therapy with a double or triple standard dose of proton pump inhibitor is recommended as an initial diagnostic approach [1, 2, 4-6]. The results of our investigations showed that 14-day therapy with a double dose of rabeprazole (open-label trial) [3] or omeprazole (randomized, placebo controlled cross-over trial) [7] leads to a decrease in the number of total chest pain episodes and in some electrocardiographic signs of myocardial ischaemia in patients with stable angina pectoris and CAD. The pathomechanism of symptom improvement after therapy with proton pump inhibitor is mostly explained by a decrease in oesophageal mucosa injury, diminished chemo- and mechanoreceptor stimulation, as well as reduction in secondary motor reaction with hypertensive contractions of the circular and longitudinal oesophageal muscles [8, 9]. In about half of patients with CAD, related to gastric acid secretion inhibition, decrease of stimulus for the cardio-oesophageal reflex and the prevention of reflexive reduction in myocardial perfusion should also be taken into consideration $[3,7,10,11]$. Moreover, because of the proven role of changes in the central and peripheral pain threshold in pathogenesis of non-cardiac chest pain $[1,2,8,9]$, mediators of the brain-gut axis might also have potential importance in the outcome of empirical therapy with proton pump inhibitor. Recently, Dickman et al. [12] reported that acupuncture is more effective than the addition of a second proton pump inhibitor dose in therapy of heartburn in patients who failed to respond to a single dose. Because it is accepted that acupuncture works through modulation of endogenous opioids' release, the results of this study suggested involvement of the opioid system in control of GORD-related symptoms. Opioids, as the "endogenous analgesia system", play a role in mechanisms of somatic and visceral pain perception, affect behavioural processes, such as learning and memory [13], modulate the pain threshold and mood state in patients with CAD [1419] and duodenal ulcer disease [20], and regulate blood pressure, through the endorphin/encephalin balance $[13,21]$.

Because the relationships between $\beta$-endorphin plasma level and outcome of therapy with proton pump inhibitor in patients with CAD had not been studied, we estimated the changes in $\beta$-endorphin plasma level after omeprazole and placebo administration. The influence of observed changes in this opioid plasma concentration on angina symptoms severity was also assessed.

\section{Material and methods}

We studied 48 patients with obstructive CAD, proven through coronarography: 11 females (23\%) and 37 males (77\%), recruited from a cardiology outpatient clinic. They suffered from stable, recurrent, angina-like chest pain, but failed to respond to standard anti-anginal therapy. For this reason overlapping of its non-cardiac sources was suspected. The mean age of the study population was $59.6 \pm 7.2$ years. The remaining demographic and clinical data of subjects, stratified by gender, are presented in Table I. All individuals included in the experiment participated in all phases of the study and completed it. None discontinued therapy.

The investigation was performed according to the double-blind, crossover, randomized, placebocontrolled design, so patients acted as their own controls. With all the patients, an interview, physical examination, blood sampling for biochemical determination and the treadmill stress test according to the Bruce protocol (Schiller, Switzerland) were carried out. After the baseline examination, each patient was assigned a consecutive drug kit, according to the sequence of his or her participation in the investigation. Each kit consisted of two boxes with 28 identical-looking capsules containing $20 \mathrm{mg}$ of omeprazole or the placebo (filling materials without omeprazole like in capsules with omeprazole). Randomization was carried out at the stage of preparing the kits. In the first investigation phase, patients were asked to take capsules of omeprazole or the placebo for 14 days, and in the second phase patients were crossed over to the other arm (omeprazole $\rightarrow$ placebo or placebo $\rightarrow$ omeprazole). This treatment was recommended as being given in addition to therapy up to that point. The doses of this medication did not change for the entire period of the investigation. Moreover, the participants did not change their smoking and alcohol drinking habits or lifestyle. Patients were only permitted to take short-acting alkalis and nitroglycerine. Following each of the two phases of the investigation, all study procedures, i.e. the interview, physical examination, blood sampling and treadmill stress test, were repeated.

\section{Determination of $\beta$-endorphin plasma concentration}

Blood samples were collected at approximately 7:15 am, after 15 min of rest, into Lavender Vacutaner tubes containing EDTA, and gently rocked immediately after collection to ensure anti- 
coagulation. The samples were then centrifuged for $15 \mathrm{~min}$ at $4^{\circ} \mathrm{C}$ to collect the plasma, which was then kept at $-80^{\circ} \mathrm{C}$. $\beta$-Endorphin estimations in the serum were carried out according to the producer's instructions by enzyme-linked immunosorbent assay (ELISA) (MD Biosciences, Zürich, Switzerland). The test sensitivity was $0.18 \mathrm{pg} / \mathrm{ml}$, intra-assay variation $<5 \%$, inter-assay variation $<14 \%$.

\section{Statistical analysis}

Statistical analysis was conducted using a licensed version of the statistical software STATISTICA PL 5.0 for Windows. The results are presented as the mean \pm standard deviation (SD) or $n, \%$. The statistical significance of differences between females and males (Table I) was checked using unpaired Student's $t$-test and Fisher's exact test. The effect of respective interventions on the $\beta$-endorphin level was estimated using ANOVA with three repetitions and the Scheffe post hoc test, so all subjects acted as their own controls. Rank Spearman correlations between the $\beta$-endorphin plasma concentration and the values of the treadmill stress test parameters were tested.

\section{Ethics}

The study protocol was approved by the local Bioethics Committee of Nicolaus Copernicus

Table I. Demographic and clinical data of studied subjects with CAD $(n=48)$

\begin{tabular}{|c|c|c|c|}
\hline Feature & Mean \pm SD or $n(\%)$ & Females $(n=11,23 \%)$ & Males $(n=37,77 \%)$ \\
\hline Age [years] & $59.6 \pm 7.2$ & $58.8 \pm 7.3$ & $62.9 \pm 6.3$ \\
\hline Number of anginal symptoms per week & $\begin{array}{c}12.9 \pm 7.9 \\
\text { (median = 8; } \\
\text { range }=5-35 \text { ) }\end{array}$ & $\begin{array}{l}13.4 \pm 5.9 \\
(\text { median }=12 ; \\
\text { range }=6-26)\end{array}$ & $\begin{array}{c}12.8 \pm 8.5 \\
\text { (median }=10 \\
\text { range }=6-50)\end{array}$ \\
\hline $\begin{array}{l}\text { Number of patients with anginal } \\
\text { symptoms severity graded according } \\
\text { to CCS classification }\end{array}$ & $\begin{array}{l}\text { class II - } 36(75 \%) \\
\text { class III - } 12(25 \%)\end{array}$ & $\begin{array}{l}\text { class II - } 9(82 \%) \\
\text { class III - } 2(18 \%)\end{array}$ & $\begin{array}{l}\text { class II - } 27(73 \%) \\
\text { class III - } 10(27 \%)\end{array}$ \\
\hline Dyslipidaemia & $44(92 \%)$ & $11(100 \%)$ & $33(89 \%)$ \\
\hline Concentration of total cholesterol [mg/dl] & $232.7 \pm 43.8$ & $202.1 \pm 41.2$ & $184.7 \pm 25.0$ \\
\hline Concentration of LDL cholesterol [mg/dl] & $179.7 \pm 60.1$ & $121.3 \pm 36.8$ & $95.3 \pm 26.6$ \\
\hline Concentration of HDL cholesterol [mg/dl] & $49.5 \pm 12.6$ & $49.0 \pm 12.8$ & $61.2 \pm 17.6^{*}$ \\
\hline Concentration of triglycerides [mg/dl] & $234.7 \pm 111.4$ & $187.1 \pm 111.5$ & $136.3 \pm 63.3$ \\
\hline Hypertension & $24(51 \%)$ & $1(9 \%)$ & $23(90 \%)^{*}$ \\
\hline Diabetes mellitus & $14(27 \%)$ & $4(36 \%)$ & $10(27 \%)$ \\
\hline Smoking & $12(25 \%)$ & $3(27 \%)$ & $9(24 \%)$ \\
\hline History of myocardial infarction & $30(63 \%)$ & $6(54 \%)$ & $23(65 \%)$ \\
\hline History of $\mathrm{PCl}$ & $16(34 \%)$ & $3(27 \%)$ & $13(35 \%)$ \\
\hline History of CABG & $7(15 \%)$ & $2(18 \%)$ & $5(13 \%)$ \\
\hline Ejection fraction in echocardiography [\%] & $54.3 \pm 9.2$ & $54.5 \pm 9.9$ & $54.2 \pm 7.7$ \\
\hline Aspirin administration & $47(98 \%)$ & $11(100 \%)$ & $36(97 \%)$ \\
\hline$\beta$-Blockers administration & $44(92 \%)$ & $9(82 \%)$ & $35(95 \%)$ \\
\hline Calcium-blockers administration & $13(28 \%)$ & $3(27 \%)$ & $10(27 \%)$ \\
\hline ACEl administration & $39(81 \%)$ & $8(72 \%)$ & $31(83 \%)$ \\
\hline $\begin{array}{l}\text { Number of nitroglycerine tablets taken } \\
\text { per week }\end{array}$ & $\begin{array}{l}3.9 \pm 4.3 \\
\text { (median }=3 ; \\
\text { range 1-20) }\end{array}$ & $\begin{array}{c}4.6 \pm 4.9 \\
\text { (median =3; } \\
\text { range }=0-15 \text { ) }\end{array}$ & $\begin{array}{c}3.6 \pm 4.1 \\
\text { (median }=3 ; \\
\text { range }=0-20)\end{array}$ \\
\hline Long-acting nitrates administration & $22(45 \%)$ & $6(55 \%)$ & $16(43 \%)$ \\
\hline Statin administration & $45(100 \%)$ & $11(100 \%)$ & $34(92 \%)$ \\
\hline $\mathrm{BMI}\left[\mathrm{kg} / \mathrm{m}^{2}\right]$ & $28.3 \pm 3.7$ & $26.9 \pm 4.7$ & $28.7 \pm 3.4$ \\
\hline WHR & $0.93 \pm 0.07$ & $0.85 \pm 0.06$ & $0.96 \pm 0.06^{*}$ \\
\hline
\end{tabular}

$C A D$ - coronary artery disease, $P C I$ - percutaneous coronary intervention, CABG - coronary artery bypass graft, BMI - body mass index, WHR waist to hip (circumferences) ratio, ACEI - angiotensin-converting enzyme inhibitor, ${ }^{*} p<0.05$ for differences between females and males 


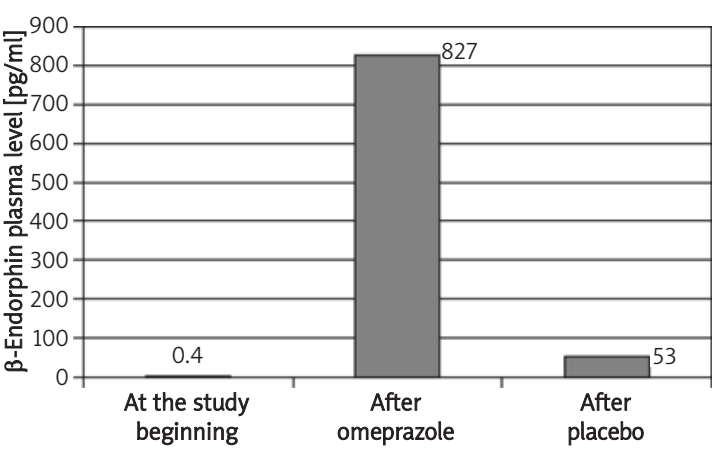

Figure 1. $\beta$-Endorphin plasma level at the study beginning, and after omeprazole and placebo administration. ANOVA, $F=36.0, p<0.0001$

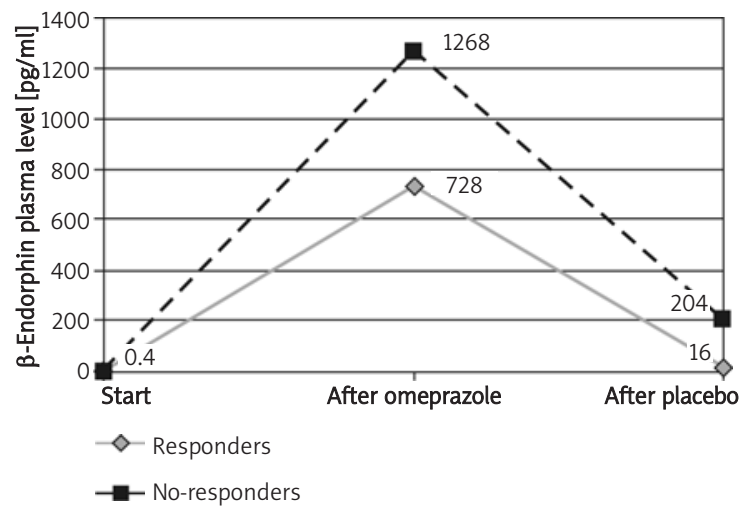

Figure 2. Differences in $\beta$-endorphin plasma level at the study start and after following study phases in patients who responded or not to the double dose of omeprazole. "Responders" were defined as subjects who reported decrease in chest pain frequency after omeprazole administration by more than $50 \%$, and "non-responders" were defined as individuals with less or lack of improvement. Interaction between study phase and response to kind of treatment, ANOVA with three repetitions: $F=2,2,06, p=0.14$

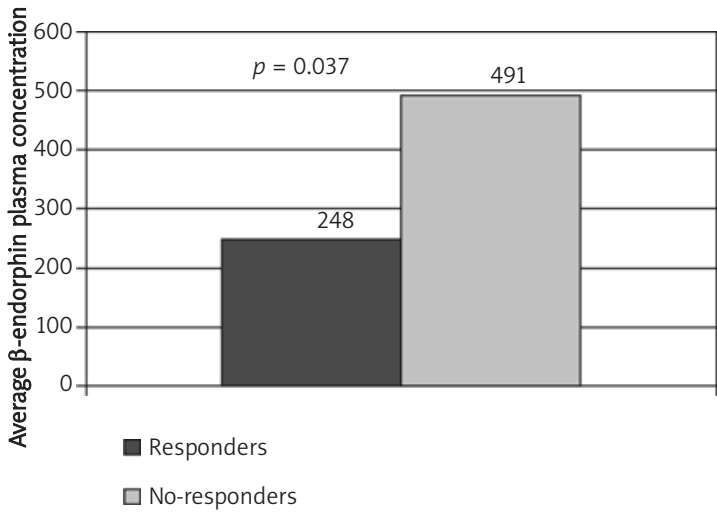

Figure 3. The main effect of kind of treatment clinical outcome on average $\beta$-endorphin plasma concentration during all three study phases. ANOVA, $F=4.9, p=0.037$
University in Torun and Collegium Medicum in Bydgoszcz, Poland. All subjects gave their informed consent prior to the start of enrolment procedures. All procedures have been conducted in compliance with the Declaration of Helsinki.

\section{Results}

The plasma $\beta$-endorphin concentration after 2-week therapy with omeprazole was significantly greater than at the beginning of the study and after the administration of the placebo (Figure 1). Response to omeprazole, defined as decrease in chest pain severity after proton pump inhibitor administration more than by half, had no significant effect on changes in $\beta$-endorphin plasma level during the investigation (interaction with the study phase) (Figure 2). However, patients who reported a greater than $50 \%$ reduction in the number of chest pain episodes (responders) following treatment with omeprazole $(n=17 / 48,35 \%)$ had a significantly lower average $\beta$-endorphin plasma concentration during the whole study period than the remaining subjects (ANOVA: main effect of clinical outcome; $F=4.9, p=0.037$ ) (Figure 3).

The changes in the $\beta$-endorphin plasma level after omeprazole therapy were related to the severity of anginal symptoms before the patient's involvement in the study, both in one- and in twofactorial analysis (ANOVA: $F=4.72, p=0.013$ ) (Figure 4). Subjects with symptoms in class III, according to the Canadian Cardiovascular Society (CCS) classification $(n=12 / 48)$, had a significantly greater plasma level of $\beta$-endorphin after 2 -week omeprazole administration than subjects ( $n=36 / 48)$ with class II anginal symptom severity (1246.3 \pm 778.0 vs. $643.6 \pm 525.5 \mathrm{pg} / \mathrm{ml}, p=0.004)$. The remaining clinical factors, such as randomization when taking omeprazole in the first study phase, gender, age, hypertension, diabetes,

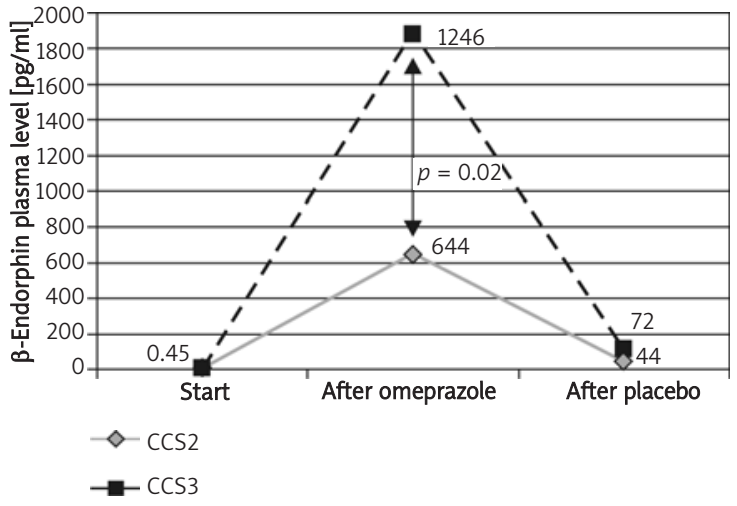

Figure 4. Differences in $\beta$-endorphin plasma level in relation to anginal symptoms severity before the patient's involvement in the study. ANOVA with three repetitions: $F=4.8, p=0.013$ 
dyslipidaemia, smoking, alcohol drinking, and the kind of CAD treatment, had no significant effect on $\beta$-endorphin plasma concentration. We did not find any statistically significant relationships between the $\beta$-endorphin plasma level and the course of the treadmill stress test, either at the start of the study or after therapy with omeprazole or the placebo.

\section{Discussion}

In our study we found an enormous increase of $\beta$-endorphin plasma concentration after 14 days' administration of a double dose of omeprazole (Figure 1). To our knowledge, this is the first report showing, in a controlled, crossover manner, an increase in the $\beta$-endorphin plasma level after omeprazole therapy. In contrast to our results, in the study by Tonnarini et al. [20], 30-day treatment with omeprazole did not influence the plasma level of $\beta$-endorphin in patients with duodenal ulcer disease. However, in other studies, the plasma $\beta$-endorphin concentration rose in response to hypoglycaemia, intense physical exercise, surgery, and psychological stress in patients with heart failure, as well as during therapy with ketoconazole and naloxone [14, 22]. Dexamethasone administration decreases this opioid's plasma level. After ketoconazole therapy the $\beta$-endorphin level increases fivefold [14] but, in our study, following omeprazole it increased on average by 2000 times and, after the placebo, by more than 100 times. Because $\beta$-endorphins play an endocrine role in brain-gut axis function [23], among others, as the endogenous analgesia system, these results might explain the improvement in anginal symptoms observed by us in $35 \%$ of patients with CAD after 14-day omeprazole administration ("responders") [7]. Increase in $\beta$-endorphin plasma level after treatment with omeprazole might also elucidate the observation made by Sarkar et al. [24] in patients with chest pain and GORD. They found that 6-week therapy with a proton pump inhibitor increases the resting oesophageal pain threshold via a decrease in central sensitization.

However, in our investigation responders to the "omeprazole test" had a lower average $\beta$-endorphin plasma concentration than subjects who failed to respond to it in one-factorial analysis (Figures 2 and 3). Moreover, the opioid level was higher in patients with greater severity of angina symptoms at the beginning of the study and was not related to the course of the treadmill stress test, including the time to the appearance of chest pain (angina threshold). These observations do not corroborate the above-mentioned hypotheses. They are also not consistent with the results of Tonnarini et al. [20], Falcone et al. [15], and Sadith et al. [18, 19]. The first showed a significantly higher $\beta$-endorphin plasma level in patients with an asymptomatic active duodenal ulcer than in subjects with a painful course of disease [20]. The second found a higher plasma level of $\beta$-endorphin in asymptomatic patients with silent ischaemia during exercise stress test than in subjects with anginal symptoms. The third observed that $\beta$-endorphin infusion decreased adenosine-provoked chest pain in male patients with CAD, whereas naloxone, an opioid receptor antagonist, induced the opposite effect $[18,19]$. Jarmukli et al. [14], although they showed that an increased $\beta$-endorphin plasma concentration augmented the peripheral pain threshold to radiant heat, similarly to our results, do not confirm a significant effect of the $\beta$-endorphin level on the angina threshold and workload during an exercise test in patients with stable angina pectoris. The different influence of $\beta$-endorphins on somatic and cardiac pain perception was explained by the specific effect of peripheral nociceptors, a distinct central mechanism of somatic and cardiac sensation perception in the thalamus, and a different central and circulating opioid effect $[14,21]$. The last explanation may elucidate improvement only in 35\% of subjects observed in our study, although the higher plasma level of $\beta$-endorphin in patients who failed to respond to the "omeprazole test" and in patients with greater severity of angina symptoms before involvement in the study is difficult to explain. One of the potential explanations of these observations may be a significantly greater hypertensive response to exercise in non-responders than in responders at the study beginning (systolic blood pressure: 174 \pm 20 vs. $157 \pm 16, p=0.004$, and diastolic blood pressure: $98 \pm 11$ vs. $91 \pm 8, p=0.04$ ). Ring et al. [21] suggested that hypertension appears to be characterised by greater levels of $\beta$-endorphins in the peripheral circulation. The second potential explanation of higher opioid plasma levels in nonresponders might be higher anxiety level, secondary to symptoms severity [14, 22]. Panic disorders are frequent in patients with CAD [25]. On the other hand, it is proven that pain causes anxiety and panic disorders increase the intensity of pain, thus demanding higher doses of analgesics, in our study endogenous $\beta$-endorphins [26]. Unfortunately, we did not measure anxiety level in our investigation. Thirdly, it may also be supposed that failure of symptoms improvement after treatment with omeprazole resulted from a very low pain threshold in "non-responders". In this way, the greater $\beta$-endorphin plasma level in such patients would be a compensatory reaction, although in our study not sufficient to give pain relief.

The potential mechanism of increase in the $\beta$-endorphin plasma concentration after omeprazole administration may only be supposed. The most probable is acting via the stimulation of pituitary 
opioid release, similar to ketoconazole [14]. Neuroendocrine activation associated with stress or anxiety provoked by symptom severity or myocardial ischaemia cannot be excluded [22], although this hypothesis is not consistent with the lower plasma level of this opioid both at the beginning of the study and following the placebo phase when symptoms severity was greater. An increase in the $\beta$-endorphin level after therapy with omeprazole may also be explained by the recently proven anti-inflammatory action of proton pump inhibitors in patients with GORD (a decrease in mucosal IL-8) [27]. It is known that the administration of proton pump inhibitors diminishes acute inflammatory cell infiltration in oesophageal mucosa. The remaining chronic inflammation dominated by T-lymphocytes is associated with an increase in $\beta$-endorphin release and a reduction in visceral pain perception [28]. This effect, also observed in patients with chronic or quiescent colitis, is explained by feedback neuroimmune cross-talk between mucosal T-cells and the enteric nervous system mediated via $\beta$-endorphin $[28,29]$. Moreover, because it is known that omeprazole inhibits cytochrome P450 (CYP) 2C19, its influence on $\beta$-endorphin clearance should also be taken into consideration [30, 31].

Our investigation has some limitations. Firstly, sample size was limited to 48 patients, although other similar cross-over trials have involved even fewer patients than our study [5, 6]. Our results, similarly to the cited works, reached statistical significance. On the other hand, together with the relatively small subject sample size the risk of an influence of confounding factors (e.g. pharmacology, age, gender, diabetes mellitus) appears. However, this bias was minimized by the cross-over study design and the use of ANOVA with three repetitions as a statistical method (each patient acted as his or her own control), as well as by subgroup analysis. All these methods decreased the role of sample size and confounding factors, especially differences in kind and dosage of medication. Secondly, in the investigation design we did not provide a "washout period". This fact may be a cause of the relatively high $\beta$-endorphin plasma level after 14 days of placebo administration, in patients who were randomized to taking omeprazole as the first drug. However, the observed changes in $\beta$-endorphin plasma level were similar irrespectively of the sequence of treatment (first week omeprazole and then placebo or the other way round). So, the lack of "washout" seems to have no significant effect on the obtained results.

In conclusion, 14-day therapy with a double dose of omeprazole significantly increases $\beta$-endorphin plasma concentration in patients with CAD. Circulating $\beta$-endorphin does not seem to be involved in the mechanism for the "omeprazole test" outcome, although an individually different effect on pain threshold cannot be excluded.

\section{Acknowledgments}

This investigation was funded by departmental sources from Nicolaus Copernicus University in Toruń, and Collegium Medicum in Bydgoszcz. We obtained a free supply of kits of omeprazole and the placebo on the basis of a written contract between POLPHARMA and Collegium Medicum in Bydgoszcz. We would like to express our sincere thanks to Associate Professor Marcin Ziółkowski for his substantial advice. None of the pharmaceutical companies has provided any commercial sources for this study. None of the authors has declared any conflict of interest in accordance with the results of this study.

In Department of Gastroenterology, Vascular Diseases and Internal Medicine, Nicolaus Copernicus University in Toruń, Collegium Medicum in Bydgoszcz the study was performed.

Conflict of interest: None declared.

\section{References}

1. Fass R, Navarro-Rodriguez T. Noncardiac chest pain. J Clin Gastroenterol 2008; 42: 636-46.

2. Dickman R, Fass R. Noncardiac chest pain. Clin Gastroenterol Hepatol 2006; 4: 558-63.

3. Świątkowski M, Budzyński J, Kłopocka M, et al. Suppression of gastric acid production may improve the course of angina pectoris and the results of treadmill stress test in patients with coronary artery disease. Med Sci Monit 2004; 10: CR524-9.

4. Flook N, Jones R, Vakil N. Approach to gastroesophageal reflux disease in primary care: Putting the Montreal definition into practice. Can Fam Physician 2008; 54: 701-5.

5. Dickman R, Emmons S, Cui $\mathrm{H}$, et al. The effect of a therapeutic trial of high-dose rabeprazole on symptom response of patients with non-cardiac chest pain: a randomized, double-blind, placebo-controlled, crossover trial. Aliment Pharmacol Ther 2005; 22: 547-55.

6. Bautista J, Fullerton H, Briseno M, Cui H, Fass R. The effect of an empirical trial of high-dose lansoprazole on symptom response of patients with non-cardiac chest pain-a randomized, double-blind, placebo controlled, crossover trial. Aliment Pharmacol Ther 2004; 19: 1123-30.

7. Budzyński J, Kłopocka M, Pulkowski G, et al. The effect of double dose of omeprazole on the course of angina pectoris and treadmill stress test in patients with coronary artery disease - a randomised, double-blind, placebo controlled, crossover trial. Int J Cardiol 2008; 127: 233-9.

8. Drewes AM, Arendt-Nielsen L, Funch-Jensen P, Gregersen $\mathrm{H}$. Experimental human pain models in gastro-esophageal reflux disease and unexplained chest pain. World J Gastroenterol 2006; 12: 2806-17.

9. Sifrim D, Mittal R, Fass R, et al. Review article: acidity and volume of the refluxate in the genesis of gastrooesophageal reflux disease symptoms. Aliment Pharmacol Ther 2007; 25: 1003-17. 
10. Chauhan A, Petch MC, Schofield PM. Cardio-oesophageal reflex in humans as a mechanism for "linked angina". Eur Heart J 1996; 17: 407-13.

11. Dobrzycki S, Baniukiewicz A, Korecki J, et al. Does gastroesophageal reflux provoke the myocardial ischemia in patients with CAD? Int J Cardiol 2005; 104: 67-72.

12. Dickman R, Schiff E, Holland A, et al. Clinical trial: acupuncture vs. doubling the proton pump inhibitor dose in refractory heartburn. Aliment Pharmacol Ther 2007; 26: 1333-44.

13. de Jong W, Petty MA, Sitsen JM. Role of opioid peptides in brain mechanisms regulating blood pressure. Chest 1983; 83: 306-8.

14. Jarmukli NF, Ahn J, Iranmanesh A, Russell DC. Effect of raised plasma beta endorphin concentrations on peripheral pain and angina thresholds in patients with stable angina. Heart 1999; 82: 204-9.

15. Falcone C, Specchia G, Rondanelli R, et al. Correlation between beta-endorphin plasma levels and anginal symptoms in patients with coronary artery disease. J Am Coll Cardiol 1988; 11: 719-23.

16. Krittayaphong R, Light KC, Golden RN, Finkel JB, Sheps DS. Relationship among depression scores, beta-endorphin, and angina pectoris during exercise in patients with coronary artery disease. Clin J Pain 1996; 12: 126-33.

17. Light KC, Herbst MC, Bragdon EE, et al. Depression and type A behavior pattern in patients with coronary artery disease: relationships to painful versus silent myocardial ischemia and beta-endorphin responses during exercise. Psychosom Med 1991; 53: 669-83.

18. Sadigh B, Berglund M, Fillingim RB, Sheps D, Sylvén C. beta-Endorphin modulates adenosine provoked chest pain in men, but not in women-a comparison between patients with ischemic heart disease and healthy volunteers. Clin J Pain 2007; 23: 750-5.

19. Sadigh-Lindell B, Sylvén C, Berglund M, Eriksson BE. Role of adenosine and opioid-receptor mechanisms for pain in patients with silent myocardial ischemia or angina pectoris: a double-blind, placebo-controlled study. J Cardiovasc Pharmacol 2003; 42: 757-63.

20. Tonnarini GF, Delle Fave G, Chianelli M, Mariani P, Negri M. Beta-endorphin in silent duodenal ulcer. Eur J Gastroenterol Hepatol 1995; 7: 357-60.

21. Ring C, France CR, al'Absi M, et al. Effects of opioid blockade with naltrexone and distraction on cold and ischemic pain in hypertension. J Behav Med 2007; 30: 59-68.

22. Oldroyd KG, Harvey K, Gray CE, Beastall GH, Cobbe SM. Beta endorphin release in patients after spontaneous and provoked acute myocardial ischaemia. Br Heart J 1992; 67: 230-5

23. Stefano GB, Zhu W, Cadet P, Bilfinger TV, Mantione K. Morphine enhances nitric oxide release in the mammalian gastrointestinal tract via the micro(3) opiate receptor subtype: a hormonal role for endogenous morphine. J Physiol Pharmacol 2004; 55: 279-88.

24. Sarkar S, Thompson DG, Woolf CJ, Hobson AR, Millane T, Aziz Q. Patients with chest pain and occult gastroesophageal reflux demonstrate visceral pain hypersensitivity which may be partially responsive to acid suppression. Am J Gastroenterol 2004; 99: 1998-2006.

25. Walters K, Rait G, Petersen I, Williams R, Nazareth I. Panic disorder and risk of new onset coronary heart disease, acute myocardial infarction, and cardiac mortality: cohort study using the general practice research database. Eur Heart J 2008; 29: 2981-8.
26. Machała W, Rysz J, Gaszyński T, Gaszyński W. Analgetic and sedative agents administered to the patients in lifethreatening conditions. Arch Med Sci 2005; 1: 138-43.

27. Isomoto H, Nishi $Y$, Kanazawa $Y$, et al. Immune and inflammatory responses in GERD and lansoprazole. J Clin Biochem Nutr 2007; 41: 84-91.

28. Verma-Gandhu M, Verdu EF, Cohen-Lyons D, Collins SM. Lymphocyte-mediated regulation of beta-endorphin in the myenteric plexus. Am J Physiol Gastrointest Liver Physiol 2007; 292: G344-8.

29. Verma-Gandhu M, Verdu EF, Bercik P, et al. Visceral pain perception is determined by the duration of colitis and associated neuropeptide expression in the mouse. Gut 2007; 56: 358-64.

30. Carlos MA, Du Souich P, Carlos R, Suarez E, Lukas JC, Calvo R. Effect of omeprazole on oral and intravenous RSmethadone pharmacokinetics and pharmacodynamics in the rat. J Pharm Sci 2002; 91: 1627-38.

31. Chandrashekhar SM, Chakrabarti A, Garg SK. Pharmacodynamic interactions of omeprazole with CNS active drugs in rats. Indian J Physiol Pharmacol 1995; 39: 74-6. 